\title{
THE COMPLEX SYSTEM OF POWER QUALITY CONTROL AND IMPROVEMENT FOR MINIMIZATION OF DELETERIOUS EFFECT ON ENVIRONMENT IN CONDITIONS OF OIL PRODUCTION ENTERPRISES
}

\author{
Emiliia V. lakovleva', Yuriy A. Sychev ${ }^{1}$ \\ 1 Electromechanical Department, Saint-Petersburg Mining University, 21 ${ }^{\text {st }}$ line 2, Saint-Petersburg, 199106, \\ Russian Federation, e-mail: sychev_yura@mail.ru
}

Received: 2017.02 .14

Accepted: 2017.03.07

Published: 2017.05.02

\begin{abstract}
The complex system of control, monitoring and improvement of power quality in power supply systems of oil production enterprises is designed, which also allows to decrease the negative influence on the environment. The main reasons for mismatch between the actual electricity quality in distribution network and the requirements for oil producing businesses, as set forth by reference documents, have been disclosed. Recommendations in connection with the arrangement and the practical implementation of technical measures for controlling and improving the quality of electric power in oil producing enterprises power supply systems are provided.
\end{abstract}

Keywords: power quality, ecological safety, oil producing

\section{INTRODUCTION}

Among the most critical factors that define electric energy saving and efficiency matters is the quality level of electric power. Modern economic situation makes electric power an asset, subject for possessing at least some quality level, as set forth by GOST 13109-97. For the last ten years, oil producing companies have been spending more than $15 \%$ of the oil prime cost and even more [1], paying electricity bills for oil mining, processing and transportation. Total costs include payments for actually consumed electric power, and the payment for the claimed power consumption during peak hours. The value of total costs may be corrected, depending on the quality level of the electric power supplied by the network power supplier, if the contract for electric power supplies between the consumer and the provider comprises the provider should pay appropriate fines, if the electric power quality does not match GOST 13109-97 regulations. In order to pay less for electricity in such a case, the power supplying company should be given the protocol of electric power quality measurement and control results for the connection points (CP), where the mismatch between the electric power quality and the GOST 13109-97 had been documented.

During the last decade, electric power supply networks in oil producing companies frequently use nonlinear load, such as regulated electric drive system frequency converters. The load of this type is the source of higher harmonics distorting the current wave and voltage in power supply network. This results in a number of bad consequences for various types of electric equipment, in particular this relates to power transformers' shorter lifespan, capacitor units degradation, false relay protection systems and automated protection systems triggering [2]. The mentioned negative consequences by-turn influence negatively on the environment, the level of ecological safety not only for region, where the oil production enterprise is situated, but also for nearest regions.

Premature failure of oiled power transformers (see. Figure 1) leads to complex repairing or full equipment replacing. Besides the utilization of oiled power transformers is difficult technological process due to containing of damage substances, which are referred to the first class of danger, ac- 


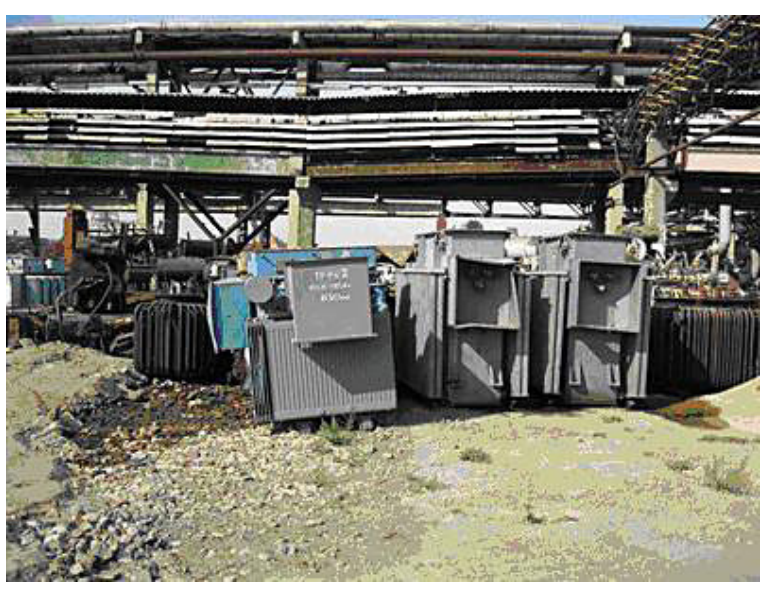

Figure 1. The oiled power transformer

cording to the Russian classification. Also it is well known that capacitor banks are the kind of garbage, referred to the second class of danger, due to containing of heavy metals, alkali and acids, which are danger for human and environment.

These facts prove the actuality of proposed decision and application of designed control system of power quality control, monitoring and improvement for decreasing of costs for recovery of failed equipment.

\section{MATERIAL AND METHODS}

GOST 13109-97 defines 11 main and 6 additional electric power quality indicators. For oil producing companies, accounting for specifics of power supplies and transformation of electric energy into the energy of other types, the following electric power quality indicators are most significant:

- steady-state voltage deviation;

- $\mathrm{n}^{\text {th }}$ harmonic voltage component coefficient;

- voltage sine wave distortion coefficient;

- voltage non-symmetry coefficient by reversed sequence;

- voltage non-symmetry coefficient by zero sequence;

- frequency deviation;

- voltage gap duration.

Electric power quality indicators are to be measured with the help of equipment that allows documenting all 11 or 6 main ones, as well as their mismatch with the norm as set forth by GOST 13109-97 that is the main relevant standard, defining the electric power quality level in the Russian Federation. Measuring devices to be used in connection therewith should be certified by Federal Agency on Technical Regulating and Metrology, and measurement results protocol, duly documented [6,7], should be provided.

The choice of electric energy quality control points in electric power supply networks of oil producing companies should be made in accordance with $[6,7]$ and based on the following recommendations:

- Electric energy quality control points should be the points of commercial supervision by oil producing companies, or other points that are the closest to the balance participation division line, where such a supervision is possible;

- Steady-state voltage deviation control points (those are in addition to the purchased electric energy control point) should better be powerconsuming outputs, as the most sensitive for voltage deviation and loss;

- It is recommended to choose the connection points, with non-linear and asymmetrical load, as control points of non-sine shape indicators and voltage non-symmetry coefficient by reversed sequence;

- It is recommended to choose buses of $0.4 \mathrm{kV}$ transformers $35 / 6(10) / 0.4 \mathrm{kV}$, feeding simultaneously three-phase and a single-phase load, as control points of voltage non-symmetry coefficient by zero sequence.

The recommended duration of periodic control of electric power quality is 7 days. Compliance between electric power quality indicators and established standards is verified by the results of their measurements per every 24 hours, separately. The total break in electric power quality indicators measurements per day, including the duration of the gaps, extra voltage and equipment outages, shall not exceed 5 minutes. The interval between regular electric power quality indicators measurements during electric power quality periodic control is established by power supply authority $[6,7]$.

Measurement error must meet the requirements specified by GOST 13109-97, items 7.1 and 7.2. Measuring devices must produce an average of electric power quality indicators measured using a rectangular measurement window with a width of $0.32 \mathrm{~s}$ (without spaces between the windows) or measuring Hanning window with a width equal to $0.4-0.5$, with an overlap of adjacent windows by $50 \%$. The final choice of the type of measuring device for electric power quality indicators control is based on comparing 
the results of their technical and economic performance and technical ability to install them in one or another point of the electrical network.

\section{RESULTS}

Implementation of the provisions on the relationship between electric power quality indicators and electricity costs can be achieved in the presence of the complex system of continuous controlling, in oil producing enterprise, and improving the quality of electric power, which allows to produce the commercial, technical and technological supervision of electric power quality, including periodic control during consideration of claims to the quality of electric power, to improve the quality of electric power using modern and efficient technical facilities and solutions.

The block diagram of measurements is being drawn during the development of a complex system for controlling electric power quality indicators (see. Figure 2), as well as selection of types and arrangement of measuring devices for controlling electric power quality indicators, selection of methods and means to transfer electric power quality indicators data to a dispatching center. The block diagram allows implementation a remote polling of one or a group of electric power quality indicators measurers, associated by RS-485 interface. The poll may also be arranged via communication office connection switched line, GSM network via RS-485/RS-232 interface converter or, if necessary, obtain data from one measurer, directly via RS-232 interface.
This allows the rapid collection of information and centralized electric power quality indicators data analysis, to obtain a complete picture of the processes occurring in the system, reduce the cost of operation of the system due to the absence of necessary trips to the substation.

Electric power quality indicators data processing is carried out by means of special software in accordance with the methodological guidelines for the controlling and analysis the quality of electric power in general purpose power supply systems, approved by State Energy Supervision (Gosenergonadzor) of the Russian Federation [6, 7].

Analysis of the actual values of electric power quality indicators, in case of their mismatch with the established norms, includes the following:

- identification of electric power quality indicators, the actual value of which does not correspond to the norm as set forth by GOST 13109-97;

- reveal of the causes of mismatch between electric power quality indicators and the GOST 13109-97;

- analysis of the mode of operation of electrical equipment, causing mismatch between electric power quality indicators and the GOST 13109-97 in distribution networks and individual consumers.

Causes of mismatch between electric power quality indicators and the established norms are revealed using the following sources of information:

- project documentation and technical specifications for the design, reconstruction and development of power supply systems and the company's electric networks;

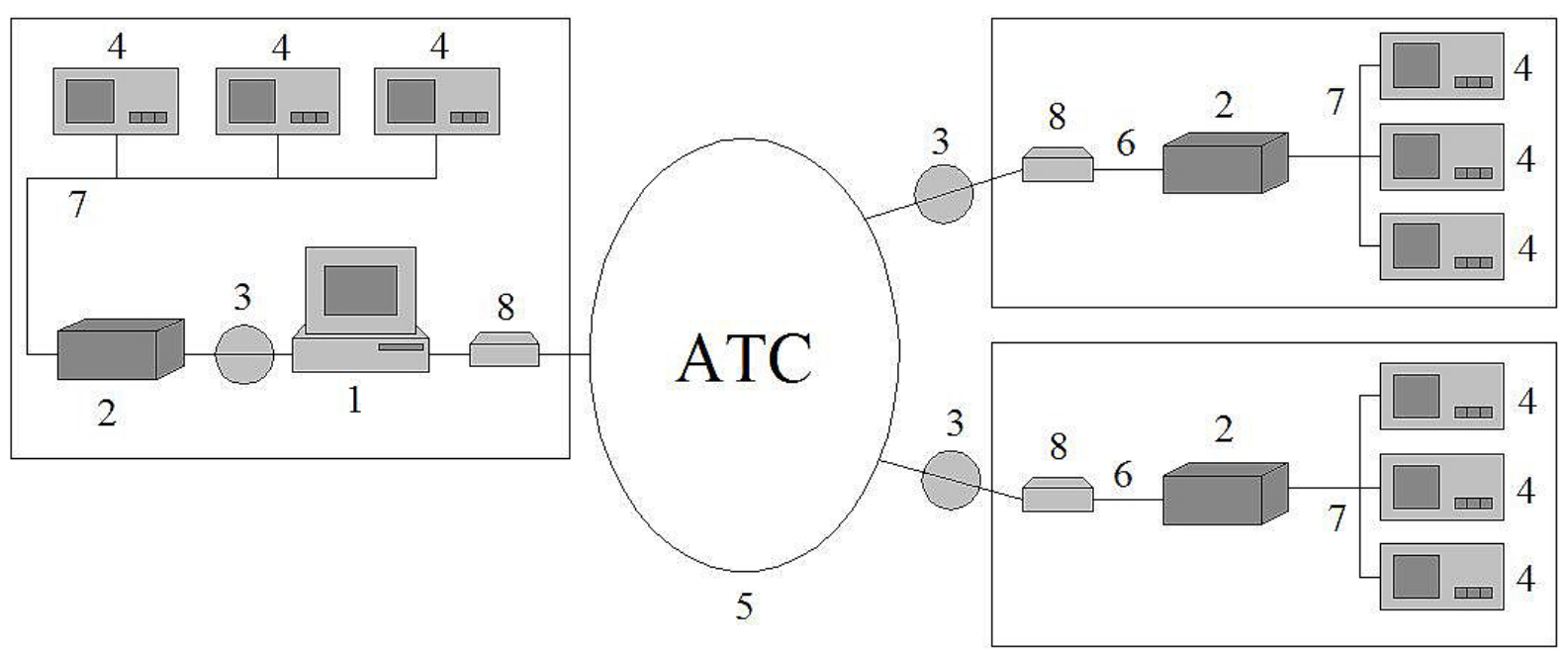

Figure 2. The block diagram of a complex system for controlling electric power quality indicators: 1 - dispatching center; 2 - RS-485/RS-232 interface converter; 3 - survey unit; 4 - controlling device of electric power quality indicators; 5 - GSM network; 6 - RS-232 cable; 7 - RS-485 interface; 8 - modem or GSM-terminal 
- data on actually consumed electric power, individual electrical devices and sub-consumers during peak hours and power system minimum load during work days, weekends and holidays, and corresponding seasons;

- calculation of electrical networks modes, including non-linear loads for normal power supply and repair schemes;

- technical conditions and signed contracts on electricity supply of a company.

The above-mentioned provisions were tested during the development of the complex system of continuous controlling of electric power quality indicators, technical and technological control of the quality of electric power for OJSC "Tatneft" [8]. As the result of the analysis of power supply systems of OJSC "Tatneft" and assessment the reasonability of the control of the quality of electric power, in 24 feeding centers stationary controlling devices of "Resource-UF2S" type are installed to control the quality of electric power. As the result of monitoring of the quality of electric power, mismatch between actual values of electric power quality indicators and the norms as set forth by GOST 13109-97 has been revealed, between the power supplier and the consumer, and individual electrical devices [8]. These electric power quality indicators include steady-state voltage deviation, voltage gap duration, voltage sine wave distortion coefficient and harmonic voltage component coefficient. For example, the voltage of $6 \mathrm{kV}$ on the buses of field substations by $5-9 \%$ higher than the nominal during 50 and more percent of the controlled period, which led to an increase in active power consumption and additional losses of electricity in the electrical system of OJSC "Tatneft". The abovementioned proved cost-efficiency of the implementation of complex systems for controlling and improving the quality of electric energy.

With the volume of expenses on necessary equipment, installation and run up around 9.5 million Russian rubles, financial return from implementation of the complex electric power quality indicators, technical and technological electric power quality monitoring system in OJSC "Tatneft" was 15.6 million Russian rubles. Therefore, the payback period hardly exceeds 0.6 year.

Based on the results of electric power quality monitoring, the best technical means or solution is selected to correct the electric power quality indicator selected in a manner, which would make it meet the requirements, as set forth by GOST 13109-97. The particular location point for the technical means selected shall be determined by the electric power supplying network layout, more specifically, the point were the power quality indicator mismatch with the GOST 13109-97 was registered. If there is no damage for technological process, the technical means installation may appear less reasonable than changing the operation mode of electric equipment affecting the level of electric power quality. Based on the results of theoretical experimental actions which were tried by OJSC "Oil company "Rosneft", OJSC "TNK-BP" and OJSC "Tatneft", a number of promising technical means and solutions were determined, as potentially capable of correcting the electric power quality indicators $[4,5]$.

More specifically, compensating higher harmonics in current and voltage in oil producing companies' electric network might be implemented in the most efficient manner via parallel active filters, which proved their efficiency after mathematical simulation and experiments in Kurmanay and Dokuchaevsk oil field power supply networks of OJSC "Orenburgneft" by OJSC "TNKBP" [2]. Electric power networks of Priobsk oil fields of LLC "RN-Yuganskneftegas" by OJSC "Oil company "Rosneft", based on the results of the abovementioned electric power quality monitoring principles implementation, potential weak points were determined for installing ten parallel active filters facilitating the voltage sine wave distortions correction.

Minimizing duration and magnitude of voltage gaps is more efficient when high-speed automatic thyristor switch systems are used [3].

Voltage deviation compensation is offered to be carried out in accordance with the algorithm for controlling the device for voltage regulation under power transformers load, based on selection of particular connection method using fuzzy logic, typically used for processing experimental statistical data about parameters of individual connections in electric power mains [5].

\section{CONCLUSIONS}

Therefore, the proposed complex system allows aligning and unification of mechanisms for controlling and quality improvement of electric power supplies for oil producing companies. Decreasing premature failure of equipment, including power transformers failure, storage batteries failure, is closely connected with minimization of deleterious effect on environment by oil produc- 
tion enterprise. Often such broken-down electrical equipment is stored in industrial area of enterprise for uncertain time before the utilization moment. At the same time power transformers and storage batteries contain different type of technical oils, which may permeate to soil, polluting it. Therefore, the proposed complex control system allows to decrease the quantity of broken-down electrical equipment for the improvement of environmental safety level of industrial object

\section{REFERENCES}

1. Abramovich B.N. 1997. Energy-efficient technologies of production, transportation and processing of mineral resources. Science in Saint-Petersburg Mining Institute (Technical University). Collection of Scientific Papers, 1, 87-90.

2. Abramovich B.N., Medvedev A.V., Starostin V.V., Abolemov E.N., Polishchuk V.V., Sychev Y. A. 2008. Industrial tests of the active filter in commercial nets of OJSC"Orenburgneft TNK-BP". Promyshlennaya Energetika, 10, 42-46.

3. Abramovich B.N., Ustinov D.A., Polyakov V.E.
2010. Dynamic stability of electrical centrifugal pump in operation. Oil Industry, 9, 104-106.

4. Abramovich B.N., Medvedev A.V., Starostin V.V., Muratbakeev E.H. 2009. Minimization of damage during oil production due to short interruptions of power supply. Promyshlennaya Energetika, 7, $25-28$.

5. Abramovich B.N., Lozovskiy S.E., Tarasov D.M. 2003. Practical issues in maintaining voltage mode at the enterprises for production, transportation and processing of oil and gas. Energy in oil production, $1,8-11$.

6. RD 153-34.0-15.501-00. 2000. Guidelines for controlling and analysis the quality of electric energy in general purpose power supply systems. Part 1. Quality control of electric energy. LLC "Research center LINVIT", Moscou

7. RD 153-34.0-15.502-02. 2002. Guidelines for controlling and analysis the quality of electric energy in general purpose power supply systems. Part 2. Analysis of the quality of the electrical energy. LLC "Research center LINVIT", Moscou.

8. Sychev Y.A. 2007. Measurement and analysis of electric power quality indicators in networks of oil producing companies. Notes of Mining Institute, 173. 109-111. 